Nevşehir Bilim ve Teknoloji Dergisi Cilt 6(2) 541-555 2017

DOI: 10.17100/nevbiltek.311306

URL: http://dx.doi.org/10.17100/nevbiltek.311306

\title{
Akıllı Malzeme Şekil Hafızalı Alaşımların Termodinamiği
}

\author{
Ömer ÇAKMAK ${ }^{1}$, Mehmet KAYA ${ }^{2, *}$ \\ ${ }^{1}$ Gebze Teknik Üniversitesi, Mühendislik Fakültesi, Malzeme Mühendisliği Bölümü, Kocaeli \\ ${ }^{2}$ Adıyaman Üniversitesi, Mühendislik Fakültesi, Metalurji ve Malzeme Mühendisliği Bölümü, Adıyaman \\ Öz
}

Akıllı malzemeler, dışarıdan uygulanan etkiler karşısında istenilen tepkileri anlık ve aralıksız bir şekilde yerine getirebilen malzemelerdir. Akıllı malzemelerin bir türü olan Şekil Hafizalı Alaşımlar (ŞHA), uygun ısıl veya mekanik etkilere maruz kaldıklarında önceki şekil ya da boyutuna dönebilme özelliğine sahiptirler. ŞHA’daki şekil değişimi mikro ve makro yapılar arasındaki faz dönüşümü ile ilgilidir. Bu faz dönüşümleri malzemenin yapısında meydana gelen 1sı ve enerji değişiminden kaynaklanmakta ve termodinamik yasalara uymaktadır. Şekil hafızalı alaşımların daha iyi anlaşılması için şekil hafıza olayının temelini oluşturan martensitik faz dönüşümünün termodinamiğinin bilinmesi gerekmektedir.

Anahtar Kelimeler: Şekil hafızalı alaşımlar, Martensitik faz dönüşümü, Termodinamik, Akıllı malzeme

\section{Thermodynamics of Smart Materiel Shape Memory Alloys}

\begin{abstract}
Smart materials can fulfill the desired reactions instantaneously and continuously in response to external applied effects. Shape Memory Alloys (SMA), a type of smart materials, have the ability to return to their previous shapes or sizes when exposed to appropriate thermal or mechanical influences. The shape change of SMA is related to the phase transformation between micro and macro structures. These phase transformations conform thermodynamic laws and are caused by heat and energy changes occurring in the structure of the material. For a better understanding of shape memory alloys, the thermodynamics of the martensitic phase transformation, which is the basis of the shape memory phenomenon, must be known.
\end{abstract}

Keywords: Shape memory alloys, Martensitic phase transformation, Thermodynamics, Smart material

\footnotetext{
"e-mail: mehmetkaya75@hotmail.com
} 


\section{Giriş}

Günümüzde teknolojik alandaki hızlı gelişmeler ve endüstriyel alandaki hızlı tüketim bilim insanlarını yeni ürünler ve üstün özellikteki yeni malzemeler üretmeye ve geliştirmeye teşvik etmektedir. $\mathrm{Bu}$ malzemelerden bir tanesi de gün geçtikçe yeni özellikleri, türleri ve uygulama alanları ortaya çıkan akıllı malzemelerdir. Akı1lı malzemeler sıcaklık, nem, basınç, ortamın asitlik derecesi (PH), elektriksel ve manyetik alan gibi çevresel veya dışarıdan uygulanan etkiler karşısında istenilen tepkilerin alınabildiği malzemelerdir. Bu akıllı malzemelerden bazıları; şekil hafızalı alaşımlar (ŞHA), termopiezoelektrik materyaller, fotovoltaik malzemeler, magnetik şiddetli materyaller, piezo malzemeler, elektrolojikal akıcılar, ışık yayan diyotlar, renk değiştiren malzemeler ve akıllı polimerlerdir. Bunlardan en yaygın olarak kullanılanları şekil hafızalı alaşımlardır [1 ve 2]. Şekil hafızalı alaşımlar uygun bir ısıl işlem veya mekanik deformasyon ile önceden tanımlı şekline ya da boyutuna dönebilme özelliğine sahip malzemelerdir. Bu alaşımlar; sağlık sektöründe (ortodontik diş telleri, stentler, endodonti alanında kullanılan aletler, ortopedik ürünler), robotik teknolojide, otomotiv endüstrisinde, sönümleme elemanlarında, havacılık ve uzay çalışmalarında, bina ve alt yapı gibi alanlarda akıllı malzeme olarak kullanılmaktadır [3-5].

Şekil hafızalı alaşımların ana karakteristiği, kritik bir sıcaklığın (dönüşüm sıcaklı̆̆ı) alt ve üst değerlerinde farklı iki şekil veya kristal yapıya sahip olabilmeleridir. Alaşım bu kritik sıcaklığın altındaki sıcaklıklarda martensit yapıda, üzerindeki sıcaklıklarda ise austenit yapıdadır. Bu özellik mikro ve makro yapılar arasındaki faz dönüşümleriyle ilgilidir. Bu faz dönüşümü; metal ve alaşımlarının farklı özellikler sergilemesinde ana etken olup fiziksel metalurjide büyük öneme sahiptir. Difüzyonsuz bir şekilde gerçekleşen bu faz dönüşüm olayı ilk olarak alman fizikçi metalurjist Adolph Martens tarafından demir esaslı alaşımlarda gözlemlendiği için martensitik faz dönüşümü diye de adlandırılmaktadır. Daha sonraki birçok araştırma ve çalışma sonucunda martensitik dönüşüm üzerine büyük gelişmeler kat edilmiş ve demir esaslı alaşımların yanı sıra soy metaller, bakır esaslı alaşımlar ve metal dışı bazı malzemelerde de gözlenmiştir [5-7].

Alaşımlardaki şekil hafıza olayı, ilk kez 1932 yılında Chang ve Read tarafından AltınKadmiyum (Au-Cd) alaşımları üzerine yapılan bir çalışma sırasında görülmüştür. Aynı yıl İsveçli fizikçi Gustav Arne Ölander Au-Cd alaşımının pseudoelastik (süperelastiklik) davranışını keşfetmiştir. ŞHA'ın teknolojik alanda kullanımı 1960'lı yıllarda gerçekleşmiştir. 1962 yılında Buehler ve arkadaşları Amerika Birleşik Devletleri'nde (ABD) Deniz Savaş Araçları Laboratuvarında eş atomlu NiTi alaşımının şekil hafıza etkisini (ŞHE) keşfetmişlerdir. Bu alaşım; bileşenleri olan NiTi ve çalıştıkları laboratuvarın isminin baş harfleri NOL (Naval Ordence Laboratuar) kullanılarak NiTiNOL adında ticarileştirilmiştir [5]. 1968 yılında Johnson ve Alicandri tarafindan şekil hafizalı NiTi alaşımı implant malzeme olarak kullanılmıştır. Söz konusu alaşım, 1972 yılında geleneksel metal alaşımlarında olmayan ısıl şekil hafıza etkisi ve süperelastiklik özelliklerinden dolayı ortodonti alanında biyomalzeme olarak, 1990’lı yılların ortalarında da tıpta stent olarak kullanılmıştır. Günümüzde şekil hafızalı alaşımların yeni özellikleri ve yeni uygulama alanları keşfedilmekle birlikte bu alandaki çalışmalar hızla devam etmektedir [2 ve 3].

Austenit-martensit faz dönüşümü malzemelerin yapısında meydana gelen 1S1 veya enerji değişimine dayanmaktadır. Isı veya enerji de termodinamik ile ilişkili olduğundan dolayı konunun daha iyi anlaşılması için termodinamik bilgisine ihtiyaç duyulmaktadır. Termodinamik terimi Latince thermos 
(1s1) ve dynamic (güç, enerji) sözcüklerinden türetilmiştir. 18. yüzyllın başlarından itibaren tekstil endüstrisindeki hızlı gelişim ile birlikte artan güç ihtiyacı, insan ve hayvan gücüyle bu ihtiyacın karşılanamaması buhar makinelerinin keşfedilmesine neden olmuştur. İngiltere'de ilk buhar makineleri 1697 ve 1712 yıllarında Thomas Savery ve Thomas Newcomen tarafindan yapılmıştır. 1765-1766 yıllarında James Watt'ın yavaş ve düşük verimliliğe sahip bu makineler üzerine olan çalışmaları ve buharın o zamana kadar bilinmeyen özelliklerini keşfetmesi bilim ve sanayi dünyası adına çok önemli gelişmelere neden olmuştur [8 ve 9]. 1824 yılında Sadi Carnot'un yazdığı "Reflections on the Motive Power of Heat and on the Machines Adopted to Develop this Power" isimli kitap ile termodinamik biliminin temelleri atılmıştır. 1849 yılında ise Lord Kelvin yaptığı bir yayında ilk kez termodinamik terimini kullanmışıır [9-11].

Termodinamik başlangıçta 1sı ve mekanik enerji ilişkilerini incelerken, günümüzde enerji ve enerji dönüşümlerinin tüm yönlerini kapsayan bir anlam ifade etmektedir. Bu kapsamı daha iyi anlayabilmek için doğadaki tüm olayların enerji ve madde dönüşümlerine bakabiliriz. Termodinamik bilimi mühendislik alanlarında ayrı bir öneme sahip olduğu gibi, güç sistemleri, iklimlendirme sistemleri, metalurji, otomobil, uçak ve uzay araçlarından bilgisayarlara kadar çok geniş uygulama alanlarına da sahiptir [9, 11- 13].

$\mathrm{Bu}$ çalışma akıllı malzemelerin bir türü olan şekil hafizalı alaşımlarda şekil hafıza olayının temelini oluşturan martensitik faz dönüşümünün termodinamiği hakkında bilgi vermeyi amaçlamaktadır. ŞHA üzerine yerli ve yabancı çok sayıda çalışma olmasına rağmen, olayın mekanizması ve termodinamiği üzerine pek fazla detaylı bilgi bulunmamaktadır. $\mathrm{Bu}$ nedenle bu çalışma özellikle ülkemizde söz konusu alaşımlar üzerine çalışan genç araştırmacılara bilgi kaynağı olacaktır.

\section{Martensitik Faz Dönüşümü}

Martensitik dönüşüm, difüzyonsuz bir faz dönüşümüdür. Difüzyonsuz faz dönüşümleri genel olarak; yüksek sıcaklıkta belirli bir kristal yapıya sahip alaşımın sıcaklık veya basınç etkisiyle veya her ikisinin birlikte tesiriyle düşük sıcaklıkta farklı bir kristal yapıya dönüşmesidir. Difüzyonsuz dönüşümde dönüşüm öncesindeki atomik komşuluklar dönüşüm sonrasında da aynı kalır. Yani dönüşümün öncesindeki ve sonrasındaki bölgelerin sadece kristal yapıları değişir, kimyasal yapıları değişmez. Şekil 1'de görüldüğü gibi martensitik dönüşüm alaşımın yüksek sıcaklıkta austenit fazdan ani soğutulmasıyla $\mathrm{M}_{\mathrm{s}}$ (Martensit başlama, start) sıcaklığında başlar ve $\mathrm{M}_{\mathrm{f}}$ (martensit bitiş, finish) sıcaklığında dönüşüm tamamlanır. Alaşım martensit fazdayken sıcaklığın tekrar arttırılması durumunda, alaşım $\mathrm{A}_{\mathrm{s}}$ (austenit başlama) sıcaklığında austenit faza dönüşmeye başlar ve $A_{f}$ (austenit bitiş) sıcaklığında yapı tamamen austenit yapıya geçerek dönüşüm tamamlanır $[6,7,14-16]$.

Martensitik dönüşümün genel özellikleri aşağıdaki başlıklar altında özetlenmiştir [4, 17, 18].

- Martensitik faz, ara bir katı çözeltidir.

- Difüzyonsuz dönüşümdür. Yani atomların dönüşüm öncesi atomik komşulukları dönüşüm sonrasinda da korunur.

- Dönüşüm sınırlı bir şekil değişikliği ile oluşur.

- Bir martensitik dönüşümde bozulmamış olarak kalan ve austenit faz ile martensit fazı ayıran düzleme habit (yerleşme, alışkanlık) düzlemi denir. Habit veya yerleşme (alışkanlık) düzlemi 
diye de adlandırılan düzlem değişmez bir düzlem olup bu düzlem üzerindeki doğrultular bozulmadan kalır (Şekil 2).

- Ana (austenit) faz ile ürün (martensit) faz kafesleri arasında sınırlı bir dönme bağıntısı vardır.

- Dönüşüm de kristal kafes hataları oluşur.
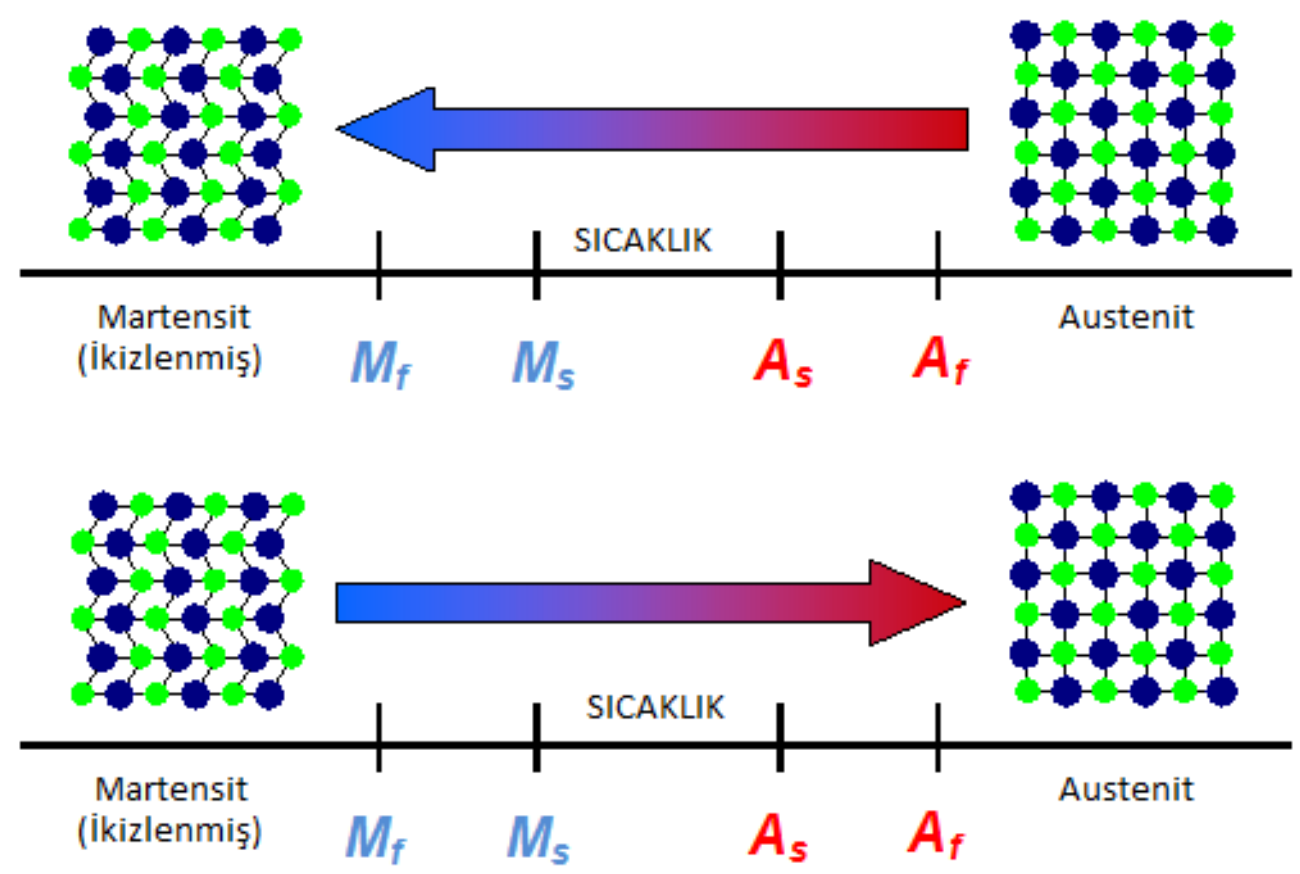

Şekil 1. Sicaklık etkisiyle geçekleşen austenit-martensit faz dönüşümünün şematik gösterimi [6].
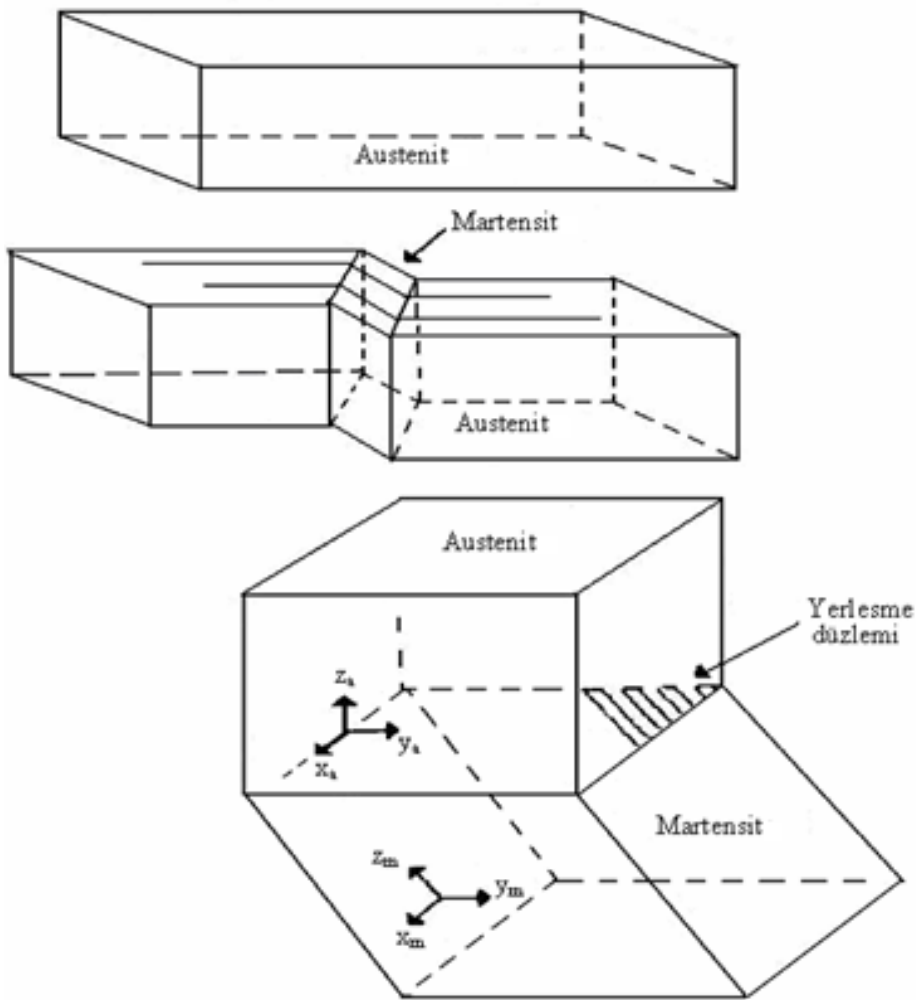

Şekil 2. Martensitik dönüşümün difüzyonsuz tabiatına bağlı düzlem ve doğrultulardaki değişim [19]. 
Martensitik dönüşüm termal etkiyle oluşum şekline göre termoelastik ve termoelastik olmayan martensitik dönüşüm diye iki türden adlandırılabilir. Sıcaklık değişimine bağlı olarak tersinir özellik gösteren martensitik dönüşümlere termoelastik faz dönüşümü denir. Termoelastik martensitik dönüşümde sıcaklı̆̆ın düşmesi ile martensit plakaları oluşur ve büyürler. Sıcaklığın tekrar arttırılması durumunda ise plakalar kaybolmaya başlar. Buradaki dönüşüm ortam sıcaklığı veya dışardan bir yüke bağlı olarak gerçekleşir. Şekil 3'de termoelastik (Au-Cd) ve termoelastik olmayan (Fe-Ni) alaşımlar hakkında bilgi veren elektrik direncindeki değişimin sıcaklık ile ilişkisi verilmektedir. Burada Fe-Ni alaşımının dönüşüm sıcaklığının histerezesi yani austenit başlangıç $\left(\mathrm{A}_{\mathrm{s}}\right)$ sıcaklığı ile martensit başlangıç $\left(\mathrm{M}_{\mathrm{s}}\right)$ sıcaklığı arasındaki fark (yaklaşık $400{ }^{\circ} \mathrm{C}$ ) çok büyüktür. Au-Cd alaşımında ise bu değer (yaklaşık $15^{\circ} \mathrm{C}$ ) çok küçüktür. Dönüşüm histerezesinin büyük olması dönüşümün gerçekleşmesi için gerekli olan serbest enerji ve itici güç arttırmaktadır [2, 20, 21].

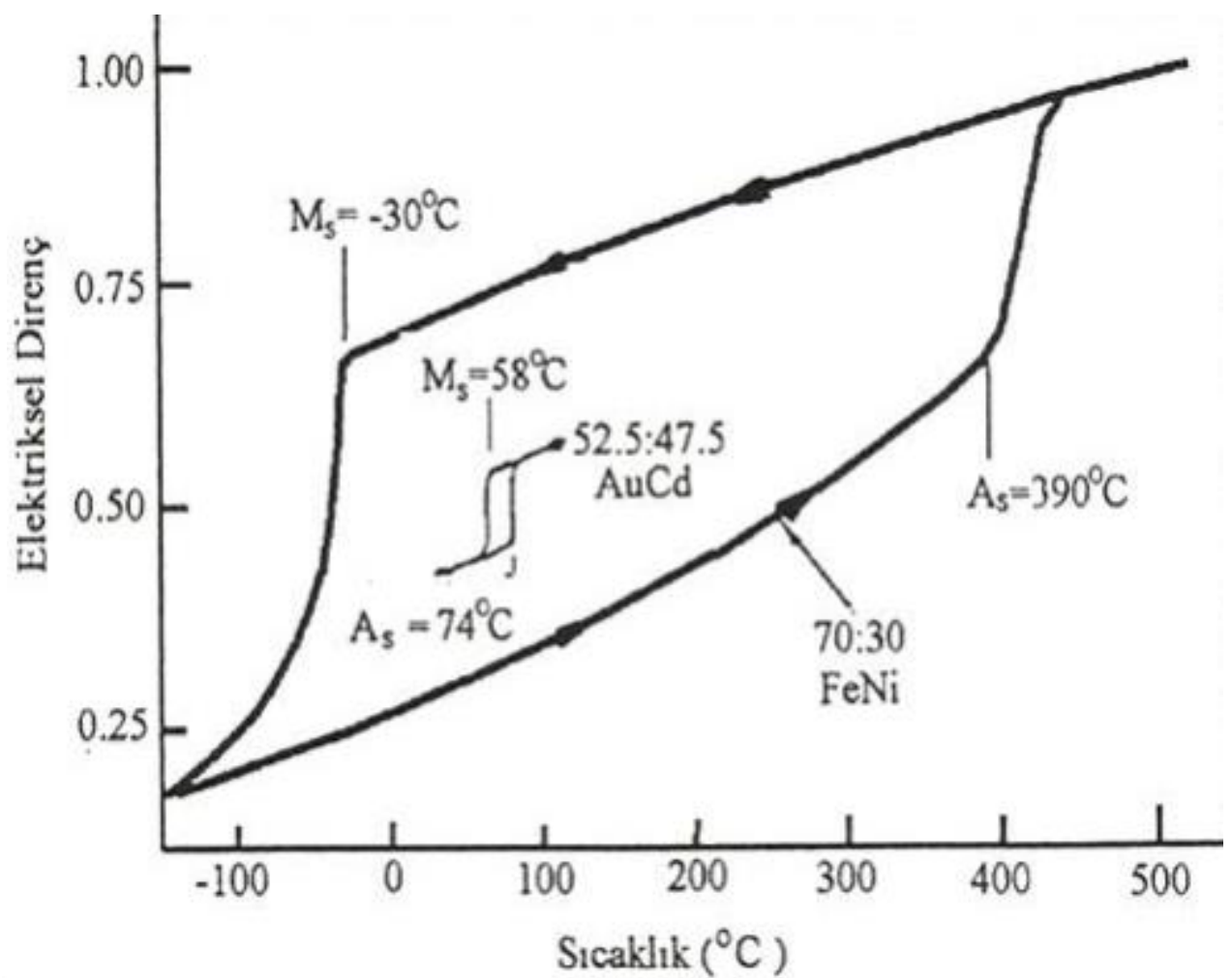

Şekil 3. Termoelastik olan (AuCd) ve olmayan (FeNi) martensit dönüşümler için sıcaklık döngülerinin karşılaştırılması [20].

Termal etkili martensitik dönüşümler izotermal ve atermal olmak üzere iki şekilde oluşur. $\mathrm{Bu}$ fazlarının, dönüşüm sıcaklığı ve dönüşüm sonrası ürünleri birbirinden farklıdır. Atermal dönüşümlerde austenit yapıdaki alaşımın sıcaklık değeri $\mathrm{M}_{\mathrm{s}}$ değerinin altındaki sıcaklıklara düşürüldüğünde yapı tamamen martensit faza dönüşür. Dönüşümün çok hızlı ve kayma deformasyon türü ile gerçekleşmesinden dolayı şekil hafıza olayı gözlenemez. İzotermal dönüşümlerde ise ana fazdaki alaşımın sıcaklığı, $\mathrm{M}_{\mathrm{s}}$ sıcaklık değerine düşürülmesiyle austenit yapı içerisinde martensit oluşmaya başlar ve $\mathrm{M}_{\mathrm{f}}$ sıcaklığında tamamlanır. İzotermal dönüşümün belirli bir sıcaklık aralığında ikizlenme deformasyon türü ile gerçekleşmesinden dolayı bu dönüşüme sahip alaşımlarda şekil hafıza olayı gözlenir $[3,22]$. 
Martensitik dönüşüm çok hızlı bir şekilde $\left(10^{-7} \mathrm{~s}\right)$ meydana geldiği için oluşum sırasında gözlenemez. Bundan dolayı dönüşümün kristolografisi dönüşüm öncesi ve sonrası fazlara ait kristolografik yapılar incelenerek ortaya konulabilir. Martensitik dönüşümde atomların komşuluklarını koruyarak kristal yapısını değiştirmesi konusundaki ilk kristalografik model 1924 yılında Bain tarafindan ortaya konulmuştur. Bain bu model de kristal örgünün martensitik dönüşüm sırasında belli bir deformasyona uğradığını iddia etmiştir. Bu modele göre yüzey merkezli kübik yapıya (fcc) sahip atomların komşulukları değişmeden, atomlar arası uzaklıkların değişmesi sonucunda hacim merkezli kübik (bcc) veya hacim merkezli tetragonal (hct) yapılara dönüşebilirler (Şekil 4) [23-25].
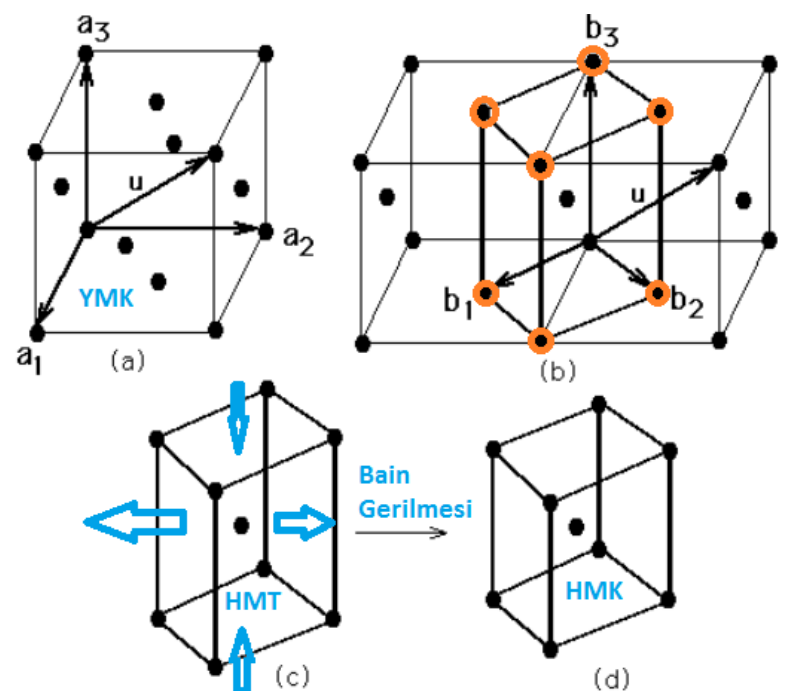

(d)

Şekil 4. Bain tarafinda modellenen ymk-hmt-hmk kristal yapı dönüşümünün mekanizması [2]

\section{Martensitik Faz Dönüşümlerinin Termodinamiği}

Bir malzemenin katı, sıvı, gaz ve plazma gibi farklı halleri faz olarak adlandırılmakla birlikte, kristal yapı olarak düşünüldüğü zaman kristal yapı özelliğine sahip bir malzeme içerisinde fiziksel ve kimyasal özellikleri aynı olan homojen bölgeler de faz olarak adlandırılır. Faz termodinamik bir denge halidir. Malzemedeki basınç, sıcaklık ve bileşim, fazların oluşumu ve dönüşümündeki etkenlerdir. Malzemeler bu parametrelere bağlı olarak farklı fiziksel şartlarda farklı kristalografik ve termodinamik özelliğe sahiptir, yani farklı fazlara dönüşebilirler. Metal ve alaşımlarda difüzyonlu ve difüzyonsuz olmak üzere iki tür faz dönüşümü vardır. Faz dönüşümleri sırasında atomların rastgele yer değiştirmesi sonucu oluşan dönüşümlere difüzyonlu faz dönüşümleri denir. Bu dönüşümlere saf metallerin katılaşması ve ötektoid dönüşüm örnek olarak verilebilir. Atomik komşulukların değişmeden sadece kristal yapının değişmesi sonucu oluşan dönüşümlerin ise difüzyonsuz faz dönüşümü olduğu önceki sayfalarda belirtildi. Şekil hafızalı alaşımların temelini oluşturan austenit-martensit faz dönüşümleri de difüzyonsuz faz dönüşümü türündendir $[1,14]$.

Martensitik faz dönüşümleri sıcaklık ve basınçla ilişsili olup birtakım termodinamik yasalara dayanmaktadır. Genel olarak termodinamik; sistemdeki 1sı, iş ve bunların arasındaki ilişkiyi, sistemdeki enerjinin dönüşümünü inceleyen bilim dalıdır. Sistemin toplam enerjisi (E); kinetik, potansiyel ve iç enerjilerinin toplamına eşittir.

$$
\mathrm{E}=\mathrm{U}+\mathrm{KE}+\mathrm{PE}
$$


Kapalı sistemlerin çoğu hal değişimi esnasında hareketsizdir. Yani kinetik ve potansiyel enerjilerinde değişim olmaz. Bu nedenle sistemin toplam enerjisindeki değişim (dE), iç enerjisindeki değişime $(\mathrm{dU})$ eşittir $(\mathrm{dU}=\mathrm{dE})$. Bu eşitlikten faydalanılarak enerjinin korunumu (termodinamiğin birinci yasası) aşağıdaki gibi bir difarensiyel denklem ile ifade edilebilir:

$$
\mathrm{dU}=\mathrm{dE}=\mathrm{dq}-\mathrm{PdV}-\mathrm{dw}
$$

Denklemde dq; sistem sınırlarındaki net 1sı değişimini, PdV; sistemin sabit P basıncına karşı hacminin dV kadar değişmesiyle dış basınca karşı yaptığı mekanik iş miktarını ve dw; sistemin diğer dış kuvvetlere karşı yaptığı net işi ifade etmektedir. Sistemin diğer dış kuvvetlere karşı yaptığı iş ihmal edildiğinden $(\mathrm{dw}=0)$ enerjinin korunumu kanunu genellikle;

$$
\begin{aligned}
& d U=d E=d q-P d V \\
& d U+P d V=d q \text { veya } d q=d E+P d V \\
& d U+F / A(A \cdot d x)=d q \\
& d U+F \cdot d x=d q \text { olur. }
\end{aligned}
$$

Eğer hacim değişimi yok ise $\mathrm{dU}=\mathrm{dq}$ olur. Yani $\mathrm{dE}=\mathrm{dq}$ olarak ifade edilir $[9,10,12,13]$. Bu eşitlik bize sistemin toplam enerjisinde meydana gelen değişimin, dışarıdan aldığı 1sı enerjisine eşit olduğunu ifade etmektedir. Kapalı bir sistemin basıncı sabit kalmak şartıyla hacmi $\mathrm{V}_{1}$ 'den $\mathrm{V}_{2}$ 'ye değişirse enerjisi de (dE = dq-PdV' ye göre) $E_{1}$ 'den $E_{2}$ 'ye değişir ve dolayısı ile sistemin iç enerjisi;

$$
\mathrm{dE}=\mathrm{E}_{2}-\mathrm{E}_{1}=\mathrm{dq}-\mathrm{P}\left(\mathrm{V}_{2}-\mathrm{V}_{1}\right)
$$

olarak yazılabilir.

$$
\begin{aligned}
& \mathrm{dq}=\mathrm{dE}+\mathrm{PdV} \text { termodinamiğin I. kanuna göre } \\
& \mathrm{dq}=\mathrm{E}_{2}-\mathrm{E}_{1}+\mathrm{P}\left(\mathrm{V}_{2}-\mathrm{V}_{1}\right) \\
& \mathrm{dq}=\left(\mathrm{E}_{2}+\mathrm{PV}_{2}\right)-\left(\mathrm{E}_{1}+\mathrm{PV}_{1}\right) \text { olur. }
\end{aligned}
$$

Buradan E+PV ifadesi entalpi $(\mathrm{H})$ veya sistemin sahip olduğu enerjinin toplamı olarak adlandırılır. Entalpinin ölçü birimi (Cal/atom) veya (Cal/mol)' dür [9-13]. Entalpi (H) maddenin miktarına, basıncınca ve fiziksel haline bağlıdır.

$\mathrm{E}+\mathrm{PV}=\mathrm{H}$ ifadesi termodinamiğin $\mathrm{I}$. kanununda $(\mathrm{dq}=\mathrm{dE}+\mathrm{PdV})$ yerine yazılmak istenirse; $\mathrm{I}$. kanun $\mathrm{dq}=\mathrm{dH}$ olarak yazılabilir. Yani sisteme verilen 1sı değişimi entalpi değişimine eşit olur. Bir maddenin veya sistemin birim sıcaklık değişmesiyle aldığı veya verdiği isı enerjisi miktarı ise isı kapasitesi (c) olarak adlandırılır ve $\mathbf{c}=\mathbf{d q} / \mathbf{d T}$ olarak ifade edilir. Sıcaklığın $\Delta \mathrm{T}$ kadar değişmesi durumunda toplam miktardaki $(\mathrm{m}) 1 \mathrm{~s} 1$ değişimi ise $\mathrm{Q}=\mathrm{mc} \Delta \mathrm{T}$ olarak adlandırılır.

$\mathrm{dq}=\mathrm{dH}$ olduğundan, $\mathrm{c}=\mathrm{dH} / \mathrm{dT}$ ve böylece $\mathrm{dH}=\mathrm{c} . \mathrm{dT}$ elde edilir. Her iki tarafin integrali alındığında;

$$
\mathrm{dH}=\mathrm{H}_{2}-\mathrm{H}_{1}=\int \mathrm{c} . \mathrm{dT},
$$

entalpi değişim $(\mathrm{dH})$ ifadesi elde edilir ki bu değerler genelde basıncın değişmediği durumlarda kullanılır [9-11].

Bir sistem içerisinde faz değişimi esnasında enerjinin korunduğu bilinmektedir. Sistem içerisinde düzensizlik var ise hal değişimi veya diğer adıyla faz değişimi kaçınılmaz bir durumdur. Sistemdeki düzensizlik entropi olarak adlandırılır ve termodinamiğin II. yasasına göre faz değişiminin değişip değişmeyeceğini, değişecekse değişimin hangi yönde gerçekleşeceğini belirlemeye yarar [9-12]. 
Bir sistemin 1sısı, T sıcaklığında dq kadar dönüşümlü (tersinir) olarak değiştiği durumda bu sistemin entropisi $(\mathrm{S})$;

$$
\mathrm{dS}=\mathrm{dq} / \mathrm{T}
$$

kadar değişmiş olur.

$$
\mathrm{dq}=\mathrm{dH} \text { ve } \mathrm{dH}=\mathrm{c} . \mathrm{dT} \text { olduğundan } \mathrm{dS}=\mathrm{dH} / \mathrm{T}=\mathrm{c} \cdot \mathrm{dT} / \mathrm{T}
$$

eşitliğine dönüşür.

$$
\mathrm{dS}=\mathrm{S}_{2}-\mathrm{S}_{1}=\int \mathrm{c} . \mathrm{dT} / \mathrm{T} \text { veya } \mathrm{dS}=\mathrm{dH} / \mathrm{T}
$$

$\mathrm{Bu}$ denklem bize eğer bir sitemdeki entalpi değişimini bilirsek entropi değişimini de hesaplayabileceğimizi göstermektedir.

Martensitik faz dönüşümü sıcaklık etkisi ile gerçekleşiyorsa termal etkili faz dönüşümü diye adlandırılır. Austenit-martensit dönüşüm esnasında kristal yapı çevresi ile 1sı ve iş şeklinde enerji değişimi gerçekleştirir. Böylece sistemin enerjisinde bir artış veya azalma meydana gelir. Çevresi ile etkileşim sırasında meydana gelen enerji değişimi Denklem 3'de gösterildiği gibi $\mathrm{dE}=\mathrm{dq}-\mathrm{PdV}$ şeklinde yazılabilir. Termodinamiğin II. yasasına göre dq = T.dS olduğundan Denklem 3 aşağıdaki gibi yazılabilir.

$$
\mathrm{dE}=\mathrm{T} \cdot \mathrm{dS}-\mathrm{PdV}
$$

Sistemin denge durumu enerjisi ile ifade edilir. Kararlı bir sistem en düşük enerjili faz düzeninde bulunma eğilimindedir. Sistemin daha dengeli bir hal alması sırasında faz dönüşümü gerçekleşir. Sabit sıcaklık ve basınçtaki dönüşümler için sistemin denge durumu Gibbs serbest enerjisi ile ifade edilir. Genel olarak Gibss serbest enerjisi (G) bir reaksiyonun T sıcaklığındaki serbest enerji değişimi, faz dönüşümü esnasındaki ürünler ve reaktanların serbest enerjilerinin farkına eşittir ve [9, 11-13, 22];

$$
\begin{aligned}
& \mathrm{G}=\mathrm{H}-\mathrm{TS} \\
& \mathrm{dG}=\Sigma \mathrm{G}_{\text {ürün }}-\Sigma \mathrm{G}_{\text {reaktan }} \\
& \mathrm{dG}=\left[\Sigma \mathrm{H}_{\text {ürün }}-\mathrm{TS}_{\text {ürün }}\right]-\left[\Sigma \mathrm{H}_{\text {reaktan }}-\mathrm{TS}_{\text {reaktan }}\right] \\
& \mathrm{dG}=\left[\Sigma \mathrm{H}_{\text {ürün }}-\Sigma \mathrm{H}_{\text {reaktan }}\right]-\mathrm{T}\left[\Sigma \mathrm{S}_{\text {ürün }}-\Sigma \mathrm{S}_{\text {reaktan }}\right] \\
& \mathrm{dG}=\mathrm{dH}-\mathrm{TdS}
\end{aligned}
$$

denklemi ile tanımlanır. $\mathrm{H}=\mathrm{E}+\mathrm{PV}$ olduğundan ve enerji ile hacim değişimi olmadığı durumdan $\mathrm{dH}=$ VdP olur. Entropi değişimi de olmadığı zaman $\mathrm{dG}=\mathrm{VdP}-\mathrm{SdT}$ olur. Basınçla sıcaklık denge şartı için ters orantilidir.

Kapalı bir sistemde $\mathrm{T}_{0}$ sıcaklığında denge şartı $\mathrm{dG}=0$ olmalıdır.

$$
\begin{aligned}
& d G=d H-T d S=0 \Rightarrow d H=T_{0} d S \\
& d H=d U+P d V+V d P
\end{aligned}
$$

Burada dG; sistemin serbest enerji değişimi, dH; sistemdeki entalpi değişimi, dS; sistemdeki entropi değişimi, dU; sistemdeki iç enerji değişimi, $\mathrm{T}_{0}$; sistemin denge sıcaklığıdır ve Şekil 9'de gösterilmektedir. Katılardaki basınç ve hacim değerlerinin (PdV ve VdP terimleri) ihmal edilebilecek derecede küçük olmasından dolayı $\mathrm{dH} \approx \mathrm{dU}$ olur ve denge durumu aşağıdaki gibi ifade edilir;

$$
\mathrm{dG}=\mathrm{dU}-\mathrm{T}_{0} \mathrm{dS}=0
$$

$\mathrm{Bu}$ denklem yardımı ile sabit basınç ve hacimde sisteme aktarılan enerjinin bilinmesi (aynı zamanda faz dönüşüm entalpisi) durumunda dönüşüm esnasındaki entropi değişimi hesaplanabilmektedir $[1,13]$.

Austenit-martensit faz dönüşümlerinde, dönüşümden önce parçacıkların (atom, elektron) belirli bir kritik enerji kazanmış olmaları gerekir. $\mathrm{Bu}$ enerji Kakeshita ve arkadaşları tarafından $\Delta$ ile 
gösterilmiş̧ir. Austenit fazından martensit faza dönüşüm olasıllğı (Pc), Boltzman faktörü ile orantılıdır ve aşağıda gösterilmektedir.

$$
\mathrm{Pc}=\operatorname{Poexp}(-\Delta / \mathrm{KbT})
$$

Burada Po ve Kb; dönüşümden önceki durum ve Boltzman sabitidirler [33].

Martensitik dönüşüm soğutmanın etkisi ile $\mathrm{M}_{\mathrm{s}}$ sıcaklığında oluşmaya başlar ve $\mathrm{M}_{\mathrm{f}}$ sıcaklığında dönüşüm tamamlanır. $M_{s}$ sıcaklığında martensitin çekirdeklenmesi için gereken itici güç, Denklem 15 'den yararlanılarak;

$$
\mathrm{G}=\mathrm{H}-\mathrm{TS} \rightarrow \Delta \mathrm{G}=\Delta \mathrm{H}-\mathrm{T} \Delta \mathrm{S},
$$

denge durumunda $\Delta \mathrm{G}=0$ olduğundan,

$$
\begin{aligned}
\Delta \mathrm{H} & =\mathrm{T} \Delta \mathrm{S} \text { ve böylece } \Delta \mathrm{S}=\Delta \mathrm{H} / \mathrm{T}_{0} \\
\Delta \mathrm{G} & =\Delta \mathrm{H}-\left(\mathrm{T} \Delta \mathrm{H} / \mathrm{T}_{0}\right)=\Delta \mathrm{H}\left(\mathrm{T}_{0}-\mathrm{T}_{\mathrm{Ms}}\right) \\
\Delta \mathrm{G} & =\Delta \mathrm{H}\left(\mathrm{T}_{0}-\mathrm{M}_{\mathrm{s}}\right) / \mathrm{T}_{0}
\end{aligned}
$$

şeklinde verilir [2].

$\mathrm{T}_{0}$ ve Ms değerleri (Şekil 5) arasındaki sıcaklık farkı nedeniyle açığa çıkan enerji ise, Kimyasal Serbest Enerji veya Kimyasal İtici Enerji olarak adlandırılır. Bu enerji, dönüşüm için gereken itici kuvveti ortaya çıkarır. Bununla birlikte dışarıdan uygulanacak mekanik bir kuvvet, itici kuvvete ek bir katkı yapacağı için dönüşme oranını arttırır [30, 31, 34, 35].

Austenit ve martensit arasındaki termodinamik denge sıcaklığı, $\mathrm{T}_{0}$; iki faz arasındaki serbest enerjinin eşitliliğidir ve;

$$
\mathrm{T}_{0}=\Delta \mathrm{H}^{\mathrm{a} / \mathrm{m}} / \Delta \mathrm{G}^{\mathrm{a} / \mathrm{m}}
$$

denklemi ile ifade edilmektedir.

Kristal yapı bu denge $\left(T_{0}\right)$ sıcaklığından hızlı soğutulursa kritik bir $\mathrm{M}_{\mathrm{s}}$ sıcaklığından sonra, austenit kristal yapı içerisinde martensit yapı oluşmaya başlar. $\mathrm{T}_{0}$ sıcaklığının altındaki sıcaklıklarda iki faz arasındaki serbest enerji farkı sıfırdan büyüktür ve martensit fazın serbest enerjisi daha küçüktür. Daha önce belirtildiği gibi kararlı bir yapı en düşük enerjili faz düzeninde bulunma eğiliminde olduğundan, martensit faz daha kararlıdır. Denge sıcaklığının üzerindeki sıcaklık değerlerinde ise austenit faz daha kararlıdır [22, 30, 31, 34].

Pratik olarak düşünüldüğünde martensitik dönüşümler bazı soğumalar altında kolayca oluşur. Ancak, austenit ve martensit ara yüzey oluşumu ve elastik gerinme enerjisinden dolayı bu dönüşüm süreci ekstra enerji $\left(G_{e}\right)$ gerektirir. Bu ekstra enerjiden dolayı $T_{0}$ sıcaklıklarından daha düşük $M_{s}$ değerlerinde denklem;

$$
\begin{aligned}
\left(\mathrm{M}_{\mathrm{s}}<<\mathrm{T}_{0} \text { olduğu durumda }\right) & \\
\Delta \mathrm{T} & =\mathrm{T}_{0}-\mathrm{M}_{\mathrm{s}} \\
\mathrm{M}_{\mathrm{s}} & =\mathrm{T}_{0}-\Delta \mathrm{T}=\Delta \mathrm{H} / \Delta \mathrm{S}-\left(\mathrm{G}_{\mathrm{e}} \mathrm{T}_{0}\right) / \Delta \mathrm{H} \\
\mathrm{M}_{\mathrm{s}} & =(\Delta \mathrm{H} / \Delta \mathrm{S})-\left(\mathrm{G}_{\mathrm{e}} \not_{0} / \Delta \mathrm{ST} /\right) \\
\mathrm{M}_{\mathrm{s}} & =\Delta \mathrm{H}^{\mathrm{a} / \mathrm{m}}-\mathrm{G}_{\mathrm{e}} / \Delta \mathrm{S}^{\mathrm{a} / \mathrm{m}}
\end{aligned}
$$

şeklinde ifade edilir. Benzer şekilde bu oluşumun ssıtma sırasındaki tersi durumunda $A_{f}$ denklemi;

$\left(A_{\mathrm{f}} \gg \mathrm{T}_{0}\right.$ olduğu durumda $)$

$$
\begin{aligned}
& \mathrm{A}_{\mathrm{f}}=\mathrm{T}_{0}+\Delta \mathrm{T}=(\Delta \mathrm{H} / \Delta \mathrm{S})+\left(\mathrm{G}_{\mathrm{e}} \mathrm{T}_{0} / \Delta \mathrm{H}\right) \\
& \mathrm{A}_{\mathrm{f}}=(\Delta \mathrm{H} / \Delta \mathrm{S})+\left(\mathrm{G}_{\mathrm{e}} \mathrm{f}_{0} / \Delta \mathrm{ST} / \mathrm{O}\right)
\end{aligned}
$$




$$
\mathrm{A}_{\mathrm{f}}=\mathrm{T}_{0}+\Delta \mathrm{T}=\left(\Delta \mathrm{H}^{\mathrm{a} / \mathrm{m}}+\mathrm{G}_{\mathrm{e}}\right) / \Delta \mathrm{S}^{\mathrm{a} / \mathrm{m}}
$$

şeklinde tanımlanabilir. Böylece $\mathrm{M}_{\mathrm{s}}$ ve $\mathrm{A}_{\mathrm{f}}$ deneysel değerlerinden aşağıdaki denklem çıkarılabilir;

$$
\begin{aligned}
& \mathrm{M}_{\mathrm{s}}=\mathrm{T}_{0}-\Delta \mathrm{T} \\
& \mathrm{A}_{\mathrm{f}}=\mathrm{T}_{0}+\Delta \mathrm{T} \\
& \mathrm{M}_{\mathrm{s}}+\mathrm{A}_{\mathrm{f}}=2 \mathrm{~T}_{0} \\
& \mathrm{~T}_{0}=\left(\mathrm{M}_{\mathrm{S}}+\mathrm{A}_{\mathrm{f}}\right) / 2
\end{aligned}
$$

Süperelastiklik durumunda uygulanan eksenel olmayan gerilme $(\sigma)$ ve birim şekil değiştirme $(\varepsilon)$ etkisi;

$$
\Delta \mathrm{G}^{\mathrm{a} / \mathrm{m}}=\Delta \mathrm{H}^{\mathrm{a} / \mathrm{m}}-\mathrm{T} \Delta \mathrm{S}^{\mathrm{a} / \mathrm{m}}-\sigma \mathcal{E}
$$

denklemindeki gibi hesaplanmalıdır. Verilen bir sıcaklıktaki denge durumu altında, denge gerilimi $(\sigma)$;

$$
\sigma=\left(\Delta \mathrm{H}^{\mathrm{a} / \mathrm{m}}-\mathrm{T} \Delta \mathrm{S}^{\mathrm{a} / \mathrm{m}}\right) / \mathcal{E}
$$

şeklinde elde edilir [36]. Katılarda basınç ve hacim değişimi olması durumunda entalpi değişimi Denklem 41'de ki gibi olmaktadır. Ancak katılarda basınç ve hacim değişimi ihmal edildiğinden sisteme verilen enerji ile entalpi değişimi Denklem 25 ve $\mathbf{2 7}$ 'deki gibi ifade edilir. Katılarda hacim değişiminin önemsiz olduğu durumda Denklem 41'de entalpi değeri PdV cinsinden yazıldığında sıfır olur. Ayrıca hacim değişmeyeceğinden $\mathrm{V}_{0}$ hacmi dikkate alınırsa gerilim ve sıcaklık ilişkisi;

$$
\mathrm{d} \sigma / \mathrm{dT}=-\Delta \mathrm{S} / \mathrm{V}_{0} \varepsilon
$$

şeklinde tanımlanır. Bu bağıntı Clausius-Clayperon eşitliği olarak adlandırılır [37].

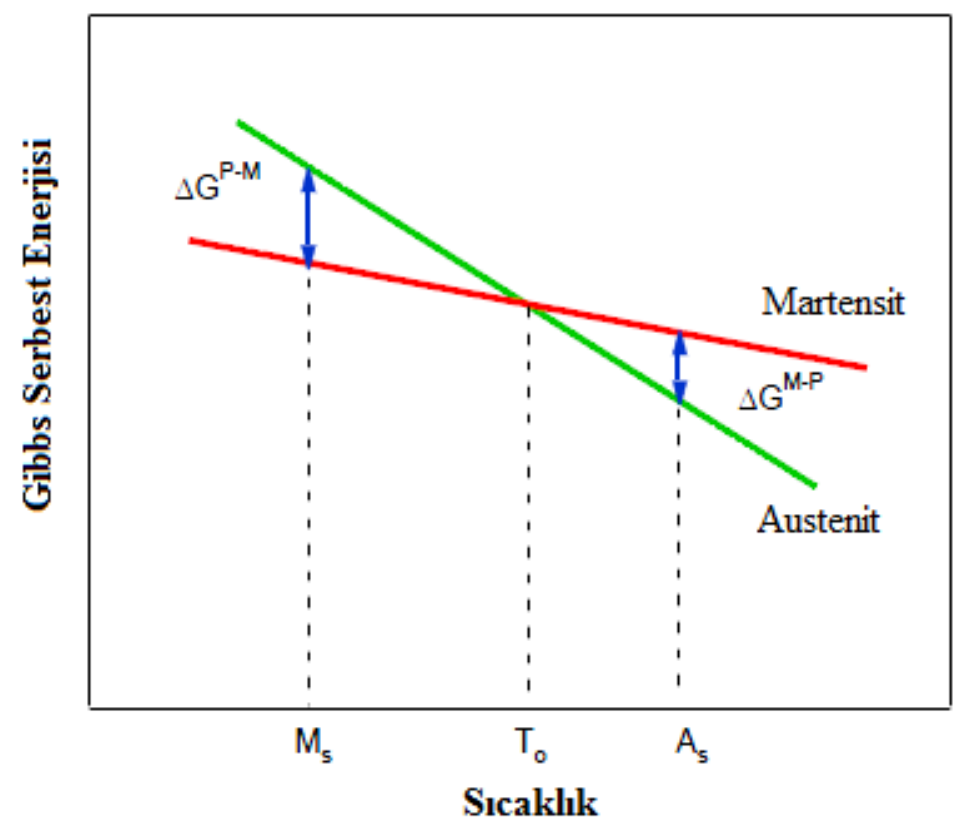

Şekil 5. Austenit ve martensit faz dönüşümlerinin serbest enerjilerinin sıcaklıkla değişimi ( $\Delta \mathrm{G}^{\mathrm{P}-\mathrm{M}}$; austenit-martensit itici kuvvet, $\Delta \mathrm{G}^{\mathrm{M}-\mathrm{P}}$; martensit-austenit itici kuvvet) $[1,10]$.

\section{4. Şekil Hafiza Olayı}

Alaşımların izotermal türü termoelastik martensitik dönüşüm göstermeleri ve deformasyonun ikizlenme ile olması sonucunda şekil hafıza etkisi ortaya çıkmaktadır. Martensit fazda deforme edilen bir alaşım austenit faz sıcaklığı üzerindeki sıcaklıklara 1sıtıldığında deformasyona uğramadan önceki ilk şekline döner (Şekil 6). Bu özelliğe sahip olan alaşımlara şekil hafızalı alaşımlar, alaşımlardaki bu özelliğe de şekil hafıza olayı denilmektedir. Şekil hafızalı alaşımlar $\mathrm{M}_{\mathrm{f}}$ sıcaklı̆̆ının altında deformasyona 
uğratıldıklarında, $\mathrm{A}_{\mathrm{f}}$ sıcaklık değerine ulaşıncaya kadar deforme edilmiş şekillerini korurlar. Alaşım, $\mathrm{A}_{\mathrm{f}}$ sıcaklığının üzerine kadar 1sıtıldığında austenit haldeki orijinal şeklini kazanır. Alaşımların deformasyondan sonra ilk şekillerine dönmesi bu tür alaşımların uygulama alanları için önemli bir özelliktir [26-28].

\subsection{Tek Yönlü Şekil Hafıza Olayı}

Martensit bitiş sıcaklığının $\left(\mathrm{M}_{\mathrm{f}}\right)$ altındaki sıcaklıkta deformasyona uğratılan alaşım, uygulanan kuvvetin kaldırılması sonucunda deformasyon öncesi ilk şekline dönemez. Kritik sıcaklık denilen austenit bitiş sıcaklığı $\left(\mathrm{A}_{\mathrm{f}}\right)$ üzerindeki bir sıcaklık değerinde alaşım deformasyon öncesi ilk şeklini kazanır. Sıcaklığın tekrar $\mathrm{M}_{\mathrm{f}}$ değerinin altına düşürülmesi sonucunda alaşım deforme olmuş şekline dönemez (Şekil 7). Alaşımlardaki bu özelliğe tek yönlü şekil hafıza olayı denir [7, 30, 31].

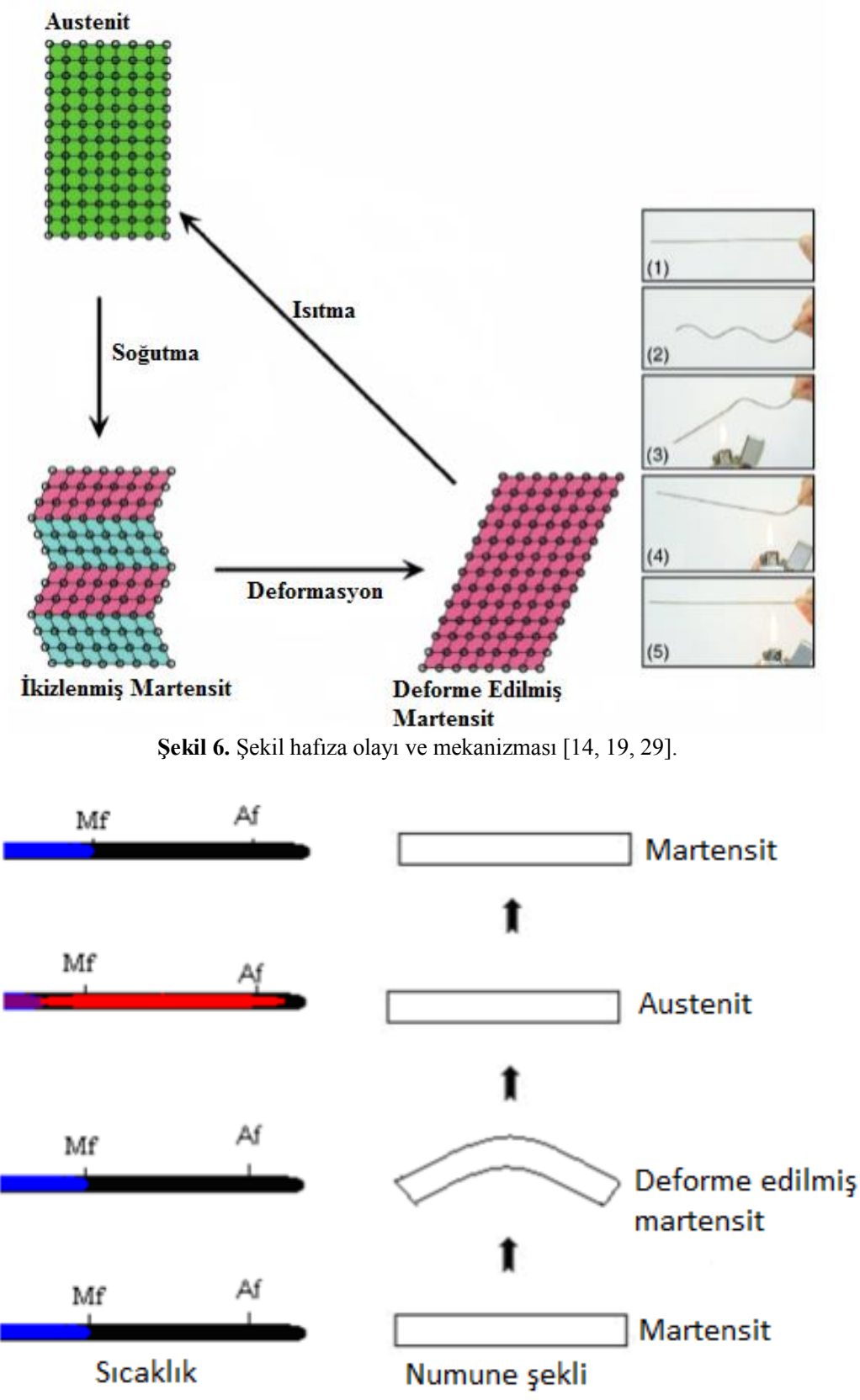

Şekil 7. Tek yönlü şekil hafiza olayı şematik gösterimi [32]. 


\section{2. Çift Yönlü Şekil Hafıza Olayı}

Martensit bitiş sıcaklığından düşük sıcaklıklarda $\left(\mathrm{T}<\mathrm{M}_{\mathrm{f}}\right)$, martensit fazdaki alaşım deformasyona uğratıldıktan sonra uygulanan kuvvetin kaldırılmasıyla tek yönlü şekil hafıza olayında olduğu gibi deforme edilmiş şeklini korur. Sıcaklık değerinin austenit bitiş sıcaklığının üzerindeki sıcaklıklara $\left(T>A_{f}\right)$ çıkartılmasıyla austenit fazdaki alaşım deforme edilmemiş ilk halini alır. Orijinal şeklini alan numune tekrar martensit bitiş sıcaklı̆̆ının $\left(\mathrm{T}<\mathrm{M}_{\mathrm{f}}\right)$ altındaki bir sıcaklık değerine soğutulduğunda deforme edilmiş şeklini kazanırsa (Şekil 8) alaşımlardaki bu özelliğe çift yönlü şekil hafıza olayı denir. Çift yönlü şekil hafıza olayı alaşımlara eğitim yaptııılması ile elde edilir. Alaşım martensit fazda iken her defasında dışarıdan bir kuvvet ile deformasyona uğratılır ve tekrardan 1sıtılır. Böylece belirli bir tekrardan (20-30 defa) sonra alaşım soğutma durumunda da deforme edilmişs şekline kendiliğinde dönüşerek 1sıtma ve soğutma ile şekil değiştirerek çift yönlü şekil hafiza olayını kazanmış olur [1, 16, 30, 31].

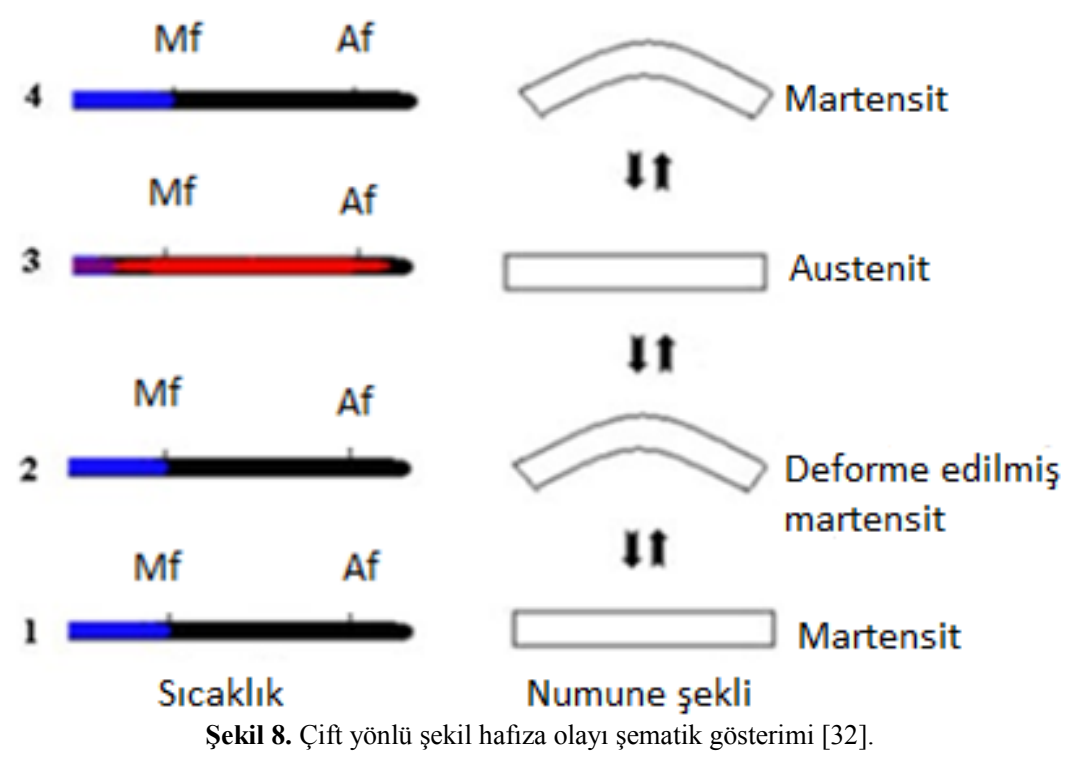

\subsection{Süperelastiklik}

Şekil hafizalı alaşımların bir diğer önemli özelliği de suni elastiklik olarak da bilinen süperelastiklik özelliğidir. Alaşım $A_{f}$ sıcaklığı üzerinde iken alaşıma mekanik kuvvet uygulanması ile martensitik dönüşüm gerçekleşir ve deformasyon meydana gelir. Yükün kaldırılmasıyla alaşımda tekrar austenit fazı meydana gelir ve alaşımda deformasyon kaybolarak elastik şekilde tekrar ilk şeklini alır. Alaşımlardaki bu tür dönüşümler süperelastiklik (suni elastiklik) olarak adlandırılır. Şekil 9.a ve b’ de bu olay şematik olarak gösterilmiştir. Suni elastiklik özelliği alaşımlarda kalıcı şekil değişimi olmaksızın yaklaşık \% 8 birim şekil değişiminde süperelastik olarak geri kazanılır $[2,14,16,21]$.

Şekil hafızalı alaşımların elastiklik oranı alternatif malzemeler ile kıyaslandığın da 20 kat daha fazladır. Bu özelliğinden dolayı özellikle medikal alanda diş tellerinin, stentlerin ve ince duvarlı tüplerin yapımında kullanılmaktadır [14]. 


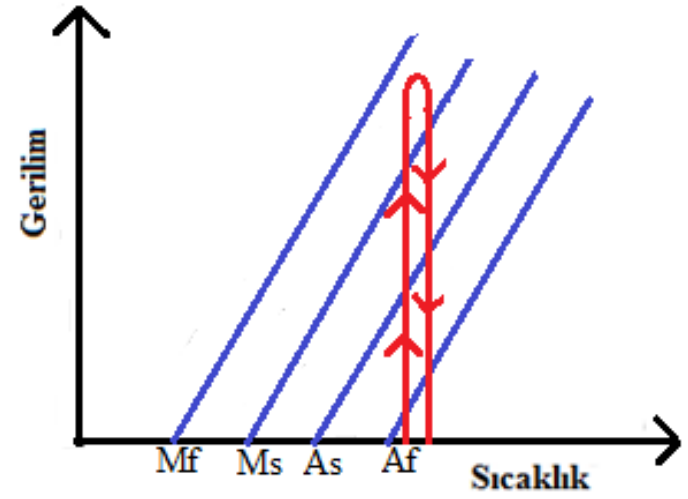

-a-

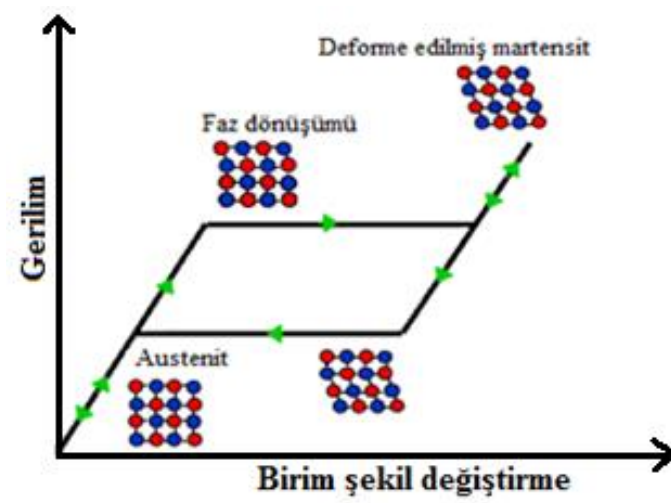

-b-

Şekil 9. Süperelastik mekanizmasının şematik gösterimi [2].

\section{Sonuçlar}

Akıllı malzemelerin bir türü olan ŞHA’ın temel özelliği kritik bir sıcaklık değerinin altında ve üzerinde farklı iki kristal yapıya sahip olması ve ayrıca bu yapılardan yüksek sıcaklıkta (austenit) düşük sıcaklık yapısına (martensit) geçiş esnasında yapıda ikizlenmelerin meydana gelmesidir. $\mathrm{Bu}$ tür alaşımlarda yüksek sıcaklık austenit fazda soğutma esnasında ekzotermik reaksiyonla martensit yapının oluşumu ve tekrar ısıtma sırasında endotermik reaksiyonla austenit fazın oluşumu söz konusudur. Austenit fazdan martensit faza geçiş difüzyonsuz bir faz dönüşümü olup izotermal türü termoelastik martensitik dönüşüm özelliğine sahiptir. Martensitik yapının oluşumu esnasında dışarıya enerji verilirken yapıda ikizlenmeler meydana gelmekte ve bu ikizlenmeler şekil hafıza olayının gerçekleşmesine katkı sağlamaktadır. Ayrıca, martensitik yapının oluşumu çeliklerdekinin aksine kayma ile değil de ikizlenme ile meydana geldiğinden yapı yumuşaktır. Soğutma esnasında alaşımdan alınan veya 1sıtma esnasında alaşıma verilen enerjiler faz dönüşüm entalpileri kadar olup termodinamik yasalara uymaktadır. Bu alaşımlar; şekil hafiza özelliğinden dolayı sağlık sektöründe, robotik teknolojide, otomotiv endüstrisinde, sönümleme cihazlarında, havacılık ve uzay çalışmalarında, bina ve alt yapı gibi alanlarda akıllı malzeme olarak kullanılmakta ve yeni özellikleri ile uygulama alanları üzerine araştırılmalar devam etmektedir.

\section{Kaynaklar}

[1] Kaya, M., Toz metalürjisi ile üretilen şekil hatıllamalı alaşımların metalürjik ve mekanik karakteristiklerinin incelenmesi, Fırat üniversitesi, Fen Bilimleri Enstitüsü, Doktora tezi, 127s, Elazığ, 2008

[2] Kaya M., Çakmak Ö., Saygılı T., Atlı K., Şekil hafizalı alaşımlarda martensitik faz dönüşümü ve şekil hafıza mekanizması, Selçuk Üniversitesi, Teknik-online dergi 15: 157-172, 2016

[3] Ryhanen, J., Bicompatibility evaluation of nichel titanium shape memory metal alloy, Oulu university library, PhD. Thesis, 155p, Oulu, 1999

[4] Eskil, M., Seval, E., Akis, A.Ç., Şekil hatırlamalı CoNiAl alaşımlarının kristalografik özellikleri, Erciyes Üniversitesi, Fen Bilimleri Enstitüsü Dergisi, 30, 19-28, 2014

[5] Jani J.M., Leary, M., Subic, A., Gibson, M.A., A review of shape memory alloy research, applications and opportunities, Materials and Design 56: 1078-113, 2014 
[6] Arghavani J., Thermo-mechanical behavior of shape memory alloys under multiaxial loading: constitutive modeling and numerical imlementation at small and finite strains, Sharif University of Technology, Mechanical Engineering Department, PhD Thesis, 186p, 2010

[7] Otsuka, K., Ren, X., Physical metallurgy of Ti-Ni-based shape memory alloys, Progress in materials science 50, 511-678, 2005

[8] Nastasi, M., Mayer, J.W., Thermodynamics and kinetics of phase transformations induced by ion irradiation, Materials science reports 6, 3 1-51, 1991

[9] Joseph M. Powers, Lecture notes on thermodynamics, Department of aerospace and mechanical engineering, University of notre dame notre dame, Indiana 46556-5637 USA Updated 29 June 2016

[10] Porter, D.A. and Easterling, K.E., Phase transformations in metals and alloys, Second Edition, Chapman \& Hall, T.J. Press (Padstow) Ltd., UK. 107-117, 1992

[11] Max Planck, Treatise on thermodynamics, Fifth edition, Dover publications, INC, Berlin, 132, 1917

[12] John Denker, https://www.av8n.com/physics/thermo-laws.pdf

[13] Aydın, S., Metalurji ve malzeme mühendisleri için termodinamik, İstanbul: Literatür yayınları, 78,2014

[14] Mihalcz, I., Fundamental characteristics and design method for nickel-titanium shape memory alloy, Periodica polytechnic Ser. Mech. Eng. 45, 1, 75-86, 2001

[15] Santiago Anadon J.R., Large force shape memory alloy linear actuator, University of Florida, Master Thesis, 122p, 2002

[16] Daniel J. Fernandes, Rafael V. Peres, Alvaro M. Mendes, and Carlos N. Elias, Understanding the shape-memory alloys used in orthodontics, International scholarly research network, 1-6, 2011

[17] Nishiyama, Z., Martensitic transformation, Academic Press, NEW YORK, 123-136, 1978

[18] Kazanç, S., Zor etkili difüzyonsuz faz dönüşümlerinin bilgisayar benzetimi ile incelenmesi, Fırat Üniversitesi Fen Bilimleri Enstitüsü, Yüksek Lisans Tezi, 135s, Elazığ. 2000

[19] Ergen S., Hızlı katılaştııılmış şekil hafızalı Cu-Al-Be alaşımının üretimi ve karakterizasyonu, Gaziosmanpaşa Üniversitesi, Fen Bilimleri Enstitüsü, Doktora tezi, 116, 2014

[20] Khaled M.M., A study of iron based alloys by positron annihilation spectroscopy, Ghent University, PhD Thesis, 143p, Mei 2009

[21] Falvo, A., Thermomechanical characterization of Nickel-Titanium Shape Memory Alloys, Department of mechanical engineering, 2008

[22] Otsuka, K. and Ren, X., Recent development in the research of shape memory alloys, Intermetallics 7: 511-528, 1999

[23] Schiller, E.H., Heat engine driven by shape memory alloys: Prototyping and design, Thesis submitted to the Faculty of Virginia Polytechnic Institute and State University in partial fulfillment of the requirements for a degree of master of science in mechanical engineering, 122p, Virginia, 2002 
[24] Olson G.B. and Owen W.S., Martensite, ASM international, The materials information society, USA 1992.

[25] Kauffmann-Weiss, S., Kauffmann, A., Niemann, R., Freudenberger, J., Schultz, L., and Fahler, S., Twinning phenomena along and beyond the Bain Path, Metals, 4: 319-336, 2013

[26] Bernal L.I.B., Cyclic Behavior of Superelastic Nickel-Titanium and nickel titanium-chromium shape memory alloys, Georgia Institute of Technology, Master Thesis, 142p, Georgia, 2004

[27] Liu, Yinong, Liu, Yong and Humbeeck, Jan Van, Two-way shape memory effect developed by martensite deformation in NiTi, Acta mater, 47-1: 199-209, 1999

[28] Simon, A.A., Shape memory response and microstructural evolution of a severe plastically deformed high temperature shape memory alloy (NiTiHf), Submitted to the office of graduate studies of Texas A\&M University in partial fulfillment of the requirements for the degree of master of science, $134 \mathrm{p}$, Texas, 2004

[29] Brian E., Structure and thermomechanical behavior of NiTiPt shape memory alloy wires, Georgia Institute of Technology, Master Degree, 133p, Georgia, 2009

[30] Otsuka, K., Saxena, A., Deng, J., and Ren, X., Mechanism of the shape memory effect in martensitic alloys: an assessment, Philosophical Magazine, 91, 36, 4514-4535, 2011

[31] Otsuka, K., Wayman, C.M., Shape memory materials, Cambridge university press, 213p, 1998

[32] Asim Rahimatpure, Smart memory alloys, Proc. of Int. Conf. on Advances in Mechanical Engineering 1-3, 2012

[33] Kakeshita, T., Saburi, T., Shımızu, K., Effect of magnetic field and hydrostatic pressure on martensitic transformation in some memory alloys, Mat. Res. Soc. Symp. Proc., Materials Research Society 459: 269-279. 1997

[34] Marukawa, K., Tsuchıya, K. and Arai, I., Short range ordering and stabilization of the martensite phase in copper alloys, J. Phys. IV. 1995

[35] Muller, I., and Seelecke, S., Thermodynamic aspects of shape memory alloys, Mathematical and computer modelling 34, 1307-1355, 2001

[36] Yamauchi, K., Ohkata, I., Tsuchiya, K., Miyazaki, S., Shape memory and superelastic alloys, Oxford, Cambridge, Philadephia, New Delhi: Woodhead publishing, 153p, 2011

[37] L.W. Tseng, Ji. Ma, S.J. Wang, I. Karaman, M. Kaya, Z.P. Luo and Y.I. Chumlyakov, Superelastic response of a single crystalline FeMnAlNi shape memory alloy under tension and compression, Acta Materialia 89, 374-383, 2015. 